\section{International Scientific Journal Theoretical \& Applied Science}

Vera Grigoryevna Sibirtseva associate professor, $\mathrm{PhD}$, Nizhny Novgorod Academy of the Ministry of the Interior of the Russian Federation, Department of Foreign Language and Culture of Speech, Russian Federation kompara2014@gmail.com

Published: $30.09 .2015 \quad$ http://T-Science.org

SECTION 21. Pedagogy. Psychology. Innovations in the field of education.

\title{
CONTENT AND STRUCTURE OF ELECTRONIC TEXTBOOK OF RUSSIAN AS A FOREIGN LANGUAGE
}

\author{
Abstract: The paper considers the features of selecting the teaching illustrative material for the practical part \\ of a multimedia textbook on Russian as a foreign language, and describes the peculiarities of compiling a set of \\ exercises on the basis of the Russian National Corpus. The author analysed the difficulties caused by working with \\ the National Corpus of the Russian Language for educational purposes and problems emerged in the process of \\ working on a project aimed at creating an electronic textbook "The Russian verb. Word formation". \\ Key words: RNC, electronic textbook, Russian as a foreign language, lexical and grammatical exercises, \\ distance learning. \\ Language: English \\ Citation: Sibirtseva VG (2015) CONTENT AND STRUCTURE OF ELECTRONIC TEXTBOOK OF \\ RUSSIAN AS A FOREIGN LANGUAGE. ISJ Theoretical \& Applied Science 09 (29): 41-44. \\ Soi: http://s-o-i.org/1.1/TAS-09-29-10 Doi: crossef http://dx.doi.org/10.15863/TAS.2015.09.29.10
}

\section{Introduction}

The form of distance education has existed since the late 19th century, and with the advent of Internet technologies available it is firmly established in our lives.

Electronic course materials are becoming more popular than printed, and under certain conditions may not only improve the efficiency of the educational process, but also turn it into a new format. In recent years there has been an active penetration of information technologies in very traditional, well-established fields of education, one of which is teaching Russian language, in particular, Russian as a foreign language (hereinafter - RAF).

The quality of e-learning in general and e-books in particular, depends on the technologies used, because the complexity of the electronic textbook, not only impedes the perception of educational material, but also cause a certain rejection by the student. In the development of an electronic textbook on the basis of the Russian National Corpus (hereinafter - the RNC) not paid electronic publishing was preliminary analyzed, but existing network grammar manuals, available for free use.

The most interesting on-line tutorials are available at the Moscow Financial University, People's Friendship University [1], an unknown developer [5], of The Lexiteria Corporation [10].
Because the developers' plans included the use of the RNC material and software corresponding to specific linguistic requirements, as a result we had to make a pilot fragment of a textbook on RAF, aimed at the advanced level of training, work with which is free and remote.

\section{The content of the textbook}

As a fragment of the textbook the theme "The Russian verb. Prefixal word-formation" was chosen, as one of the most difficult for the assimilation by foreign students. It is assumed that in the future the electronic textbook will be supplemented with materials on other parts of speech. However, at this stage it was important to put a really achievable goal and create a product balanced from the point of view of linguistics and programming. Address to the RNC materials allowed us to avoid repetitive examples in the exercises and really focus on the living, actual word usage. At the same time, the richness of lexical composition of RNC determines the highest level of exercise difficulty, after the creation of which additional examination of linguistic data and stylistic differentiation of the material is required.

The Russian Corpus is characterized by deep, diverse, and constantly improving marking (metatext, morphological, syntactic, semantic and accent), it greatly simplified the work of the compilers in the 
selection of illustrative material. The main tasks in the preparation of textbooks included the selection of RNC examples to illustrate the rules and make up exercises. The complexity of any textbooks creation related to the exhausting search of examples, requiring considerable time costs and to the limited imagination of the author in selection of exercises.

For selection of examples in the theoretical part of the textbook it is appropriate to appeal to the RNC custom search. The portal provides a detailed instruction "How to use the corpus", but the search page is intuitively understandable and comes with handy pop-up prompts, and the search is organized logically enough, so the choice of examples with specific word forms did not cause difficulties.

For educational purposes the feature of giving results in Excel is useful, you can work with the illustrative material for one linguistic phenomenon, containing about 2,000 examples. The more wellconstructed and limited request is, the less side information is contained in the received examples. However, in the process of working with the RNC we had to deal with some difficulties.

The Corpus provides the ability to search for several words, and semantic-grammatical, so you can get a clear enough limited request. The apparent advantage of the request for RNC is the ability to change the settings of the delivery of examples, although with every new request to the search page, these settings are not saved and they have to be reentered, as RNC does not provide saving of search criteria by default.

The required examples are not always displayed with accents, although there was the possibility in search settings. Because the accent in the Russian language is non-fixed (as opposed to, for example, French or Czech languages), this feature in a textbook for foreign students is obligatory.

As for the filtering of examples in Excel, then, as it turned out, the words are only in a certain order in which the initial text search is performed (user changes of the settings are not fully taken into account), namely, the search system finds some text and selects from it all possible variants that match the specified criteria. Then it moves to the next, and analogically presents the examples. In this scheme, there is undoubtedly a positive thing: if the subject matter of the text from which the example was taken, does not fit initially, you can skip a number of examples of the same text and move to the next. But there can be many such texts, and no ability to specify the preferred, and sometimes even after consideration of all the examples that are saved in Excel, 30 verbs (needed to accomplish the original problem) were not gained. We had to think out the possible cases by analogy, limit search parameters, and view examples of specific verbs. A major drawback of RNC was a significant slowing down the server, directly proportional to the amount of simultaneously set required categories of verb (mood, tense, transitivity / intransitivity, reflexivity, the presence of semantic features).

Despite these difficulties, the search for examples for the theoretical part of the electronic textbook based on the RNC can solve two major problems faced by developers of teaching materials: first, the possibility of adjusting the search on grammatical and semantic criteria, and the subsequent issuance of the results in Excel format allows to automatically obtain a sufficient number of examples, from which we can select the required manually. Secondly, the texts that are accessed by $\mathrm{RNC}$, and really modern and only the developers' sense of proportion and taste is a criterion for the selection of the material.

If the main purpose of the selection of examples for the rules is to demonstrate the use of the verb in the required situation, in the preparation of exercises you should look for examples that are appropriate to a particular rule, and bear in mind the possibility of restoring a verb or its part (for example, the prefix) in the context.

One of the major advantages is the possibility of making the exercises, which are based on the marked video clips from Soviet and Russian feature films (RNC multimedial subcorpus), which are available on video-hosting "Yandex Video". Fragments, close to living communication, and not read by one speaker, transmitting at the same time the wealth of intonational structures of the Russian language in a professional performance - a real godsend for compilers of textbooks. Multimedia corpus permits requests providing us with sufficient material for the exercises. Each video clip is provided with decoding a replica with metamarking and marked accents. Implementation of this work by hand, without reference to the Corpus materials, is not possible. Most of the time was occupied by listening to each movie, because it was necessary to assess the overall sound quality, the breadth of the context, the presence of background noise in the replica or the dialogue.

The negative moment in the sentences selected with the help of the RNC and received in Excelformat, is that the source of many of the texts are online forums where users communicate in spoken language or jargon, often incorrectly and illiterately (the words are not always used correctly for a particular context, there are mistakes in spelling). Content aspect of this kind of examples also sometimes wears a primitive character. These drawbacks suggest that for the use in the exercises RNC examples should be thoroughly pre-filtering.

The developers' focusing on only one, rather narrow aspect of study of the verb in the Russian language, has played a positive role. The Corpus materials are so varied and diverse (for example, we can mention a variety of subcorpuses: accentologic, 
news, dialects, multimedia, training, parallel, poetic, syntax, oral) that only a clear phased work allows a detailed investigation of all its features and use them optimally in developments. In the long term exercises not only in morphology but also in syntax, stylistics, lexicology, historical morphology and other aspects of language. The plans of the developers of the project also include compilation of exercises with more extensive use of multimedia RNC subcorpus.

The above features of work with using RNC materials relate only to the content, linguistic aspects of the project, difficulties and discoveries, faced by the members of the project - programmers, whose main task was to create a structure of an electronic textbook on RAF, are no less fascinating and important.

\section{The structure of the textbook}

To link the RAF materials we use the technology for creating an electronic textbook that supports the format of the SCORM (Sharable Content Object Reference Model) to implement it in any modern system of LMS (Learning Management System). A feature of this textbook is the ability to view real-time actual examples from the RNC, and a tooltip containing the translation of words into English, the primary form of the word and the corresponding grammatical information. The theoretical part of the textbook is filled with materials pre-selected from the RNC. The main component of the theoretical part of the textbook is the rules for the use of prefixes to the verb, and a number of examples that are available after clicking the appropriate button.

Russian Additional element that improves understanding of the use of examples in the textbook is a tooltip containing the translations and grammatical information of each word. The data are generated by server software and transmitted to the user's browser, where there is only a drawing of a pop-up window with the acquired information. Obtaining the necessary information is produced on a particular signal of a student or, in terms of the program, during a certain event in the user's browser.

The main problem in the selection of examples was the lack of stress in most words. In the end, the placement of stress in words was made in all the examples. Here we consider several ways of setting an accent mark. Accent mark - a sign of nonalphabetic spelling of Russian writing, in other terms - one of the superlinear diacritical marks, is placed above the vowel corresponding to the stressed sound.

The practical part of the electronic textbook is called "The use of prefixed verbs in speech. Exercises. "To this section we added a variety of exercises on a single / multiple choice, filling gaps, specially designed video exercises, for which we selected the most relevant video clips from the multimedia RNC subcorpus posted on the videohosting "Yandex Video", and multimedia elements of HTML-text are integrated into the exercises.

The exercises are used for working out the studied rules of the use of prefixes that have been learned in the theoretical part of the textbook, reinforcement of knowledge and expanding a student's passive vocabulary. Also final control tests were added to the book, you can use them to check the quality of learning material.

In the theoretical part of the electronic textbook, in addition to the possibility to analyze the effect of rules on the sentences selected by the compiler and written in the book, the opportunity was organized to address RNC by pressing the button and pick out "live" examples. These "live" sentences are extracted in real time from the constantly renewing corpus and, therefore, always include various and actual examples of use of words. The accuracy of the semantic meaning of an example of the use of a prefix depends on the ability of a linguist - compiler of the textbook, to formulate a query to search for the RNC as narrowly as possible, to cut off possible getting of sentences in which the search word is used in another meaning.

We illustrate the mechanism described by a query that extracts examples of the use of verbs with the prefix $" v "$ and indicating the orientation inside (vbit', vtolknut', vnesti', votknut'). To illustrate the rules we should find verbs that govern accusative with the preposition $" v "$ ( $v$ komnatu $)$. To prevent getting of participles and verbs in the subjunctive and the imperative, in the lexical-grammatical search restriction by grammatical features is given: verb indicative mood. The step of searching a preposition from the verb is set (1-2 words), as often a direct object is after the verb before the preposition (vtolknul ego/malchika $v$ komnatu).

Content of request was developed and optimized so that we could always get the answer, the most relevant to the given section of the textbook. At the same time a small percentage of examples, that got into the textbook mistakenly, is possible. This is the downside of using a "live" search of examples in the Russian National Corpus. We decided to level this drawback with the help of a multipage view of search results in multiple requests to the server.

These ideas are combined and added to the page template, and then the created page is sent to the client's computer.

\section{Conclusion}

The subject of development of electronic textbooks is now, of course, important, since with the 
advent of distance education in electronic form, its active implementation to the universities and the corporate sector, new approaches to provide knowledge, fast and cheap, are required. Analysis of existing electronic textbooks of Russian as a foreign language showed that they are designed for elementary and basic level of language learning and, accordingly, contain low-level exercises. Identified gap in the basis of textbooks on RAF presented on the Internet and on digital media (namely, the lack of exercises on grammar and word formation for students of second and third certification level of language), convinced the developers of the textbook that a need has formed for using quality linguistic manuals that are devoid of drawbacks typical for this type of product.

The approach to the content side of the textbook and the developed technology can be useful for creating an electronic textbook for any foreign language. Many of the world's languages have marked national corpuses, the material of which can be used for educational purposes. The time required for selection and sorting of examples, is significantly reduced when referring to the corpuses, and the relevance of examples may be given initially, by limiting the time frame of the search. A large volume of corpus (for example, the RNC has more than 300 million words) allows you to create manuals on syntax, stylistic differentiation of speech, use of certain language constructs.

The use of deeply marked-up linguistic corpus, rich in all kinds of texts of different genres, helps to make the study of linguistic phenomena and the use of words more understandable to the student.

\section{Preprint}

Preprint of this paper is an output of the Electronic Working Paper "Development of modern electronic textbook of Russian as a foreign language: content and technology" implemented and was published on 2012.03.10 at the National Research University Higher School of Economics (HSE) by Vera Sibirtseva and co authors [3].

http://www.hse.ru/data/2012/10/03/1244581498/06HUM2012.pdf

\section{References:}

1. (2015) An interactive on-line reference grammar. Available: http://www.webmetod.Narod.ru/ddd/GlagDvig/ Index.htm (Accessed: 10.09.2015).

2. (2015) API technical specifications. MyMemory. Available: http://mymemory.translated.net/doc/spec.php (Accessed: 10.09.2015).

3. Bogdanov Dmitriy, Dmitrieva Anna, Elian Elena, Karpov Nikolay, Kleshnin Eugeniy, Markina Ekaterina, Sibirtseva Vera, Teplukhina Tatiana, Violentova Lubov (2012) "Development of modern electronic textbook of Russian as a foreign language: content and technology", Series: Humanities, WP BRP 06/HUM/2012. Available: http://www.hse.ru/org/hse/wp/prepfr_Humaniti es (Accessed: 10.09.2015).

4. Dobrushina Nina (2009) Corpora metods in education Russian // Russian National Corpus 2006-2008, 2009. SPb (in Russian) Available:http://www.ruscorpora.ru (Accessed: 10.09.2015).

5. (2007) How to use accent? // Slovomania. Available:

http://www.slovomania.ru/dnevnik/2007/08/11/ how-to-use-stress-sign (Accessed: 10.09.2015).
6. (2015) Intermediate Russian exercises. Available: http://russianmentor.net/Ru_xx/STARTHERE. HTML (Accessed: 10.09.2015).

7. Kuvshinskaya Yulia (2015) Problems of Russian stylistics. Available: http://studiorum.ruscorpora.ru/stylistics/ (Accessed: 10.09.2015).

8. Levinson Anna (2007) Using the RNC in Teaching "Rhetoric" in high school // Russian National Corpus and the problems of humanitarian education. Moscow, 2007 (in Russian).

9. (2015) Russian National Corpus. Available: http://ruscorpora.ru (Accessed: 10.09.2015).

10. (2015) The eXe project: eXeLearning. Available: http://exelearning.org/ (Accessed: 10.09.2015).

11. (2015) Verb aspects. Available: http://www.alphadictionary.com/rusgrammar/in dex.html (Accessed: 10.09.2015).

12. (2015) What is the Corpus? // Russian National Corpus. Available: http://www.ruscorpora.ru/corpora-intro.html (Accessed: 10.09.2015). 